\title{
Substance of 'phantom' cardiac masses confirmed by therapeutic outcome
}

\author{
D. Afendoulis · N. Papagiannis (D) M. Moutafi · G. Panagi · P. Voutas · S. Garoufalis · N. Smyrnioudis $\cdot$ A. Kartalis
}

Accepted: 3 May 2021 / Published online: 2 June 2021

(C) The Author(s) 2021

An 87-year-old woman presented to the emergency department of our hospital with acute-onset chest pain and a presyncopal episode. She was haemodynamically stable with sinus tachycardia and $93 \%$ oxygen saturation. Urgent transthoracic echocardiography and transoesophageal echocardiography (Fig. 1; Movie 1, Electronic Supplementary Material) demonstrated enormous, highly mobile masses in both atria, protruding into both ventricles, an intact interatrial septum, mild systolic right ventricular dysfunction and pulmonary hypertension. CT pulmonary angiography (CTPA) displayed the atrial masses and bilateral pulmonary embolism at the main pulmonary artery branches (Fig. 2a, b). Considering that our patient was at high risk of bleeding from thrombolysis [1-3] and the substance of the masses was unknown, lowmolecular-weight heparin was initiated. Duplex ultrasonography of the lower extremities and total-body computed tomography displayed no signs of deep vein thrombosis or active malignancy. One week later she was discharged in a stable condition on direct oral anticoagulants. Follow-up echocardiography and CTPA demonstrated complete resolution of the

\footnotetext{
Video online The online version of this article contains one video. The article and the video are online available (https://doi.org/10.1007/s12471-021-01587-2). The video can be found in the article back matter as "Electronic Supplementary Material".

D. Afendoulis $\cdot$ N. Papagiannis $(\bowtie) \cdot M$. Moutafi $\cdot$ P. Voutas . S. Garoufalis · N. Smyrnioudis · A. Kartalis Department of Cardiology, General Hospital of Chios, Chios, Greece

papagianik@yahoo.gr

G. Panagi

Department of Radiology, General Hospital of Chios, Chios, Greece
}

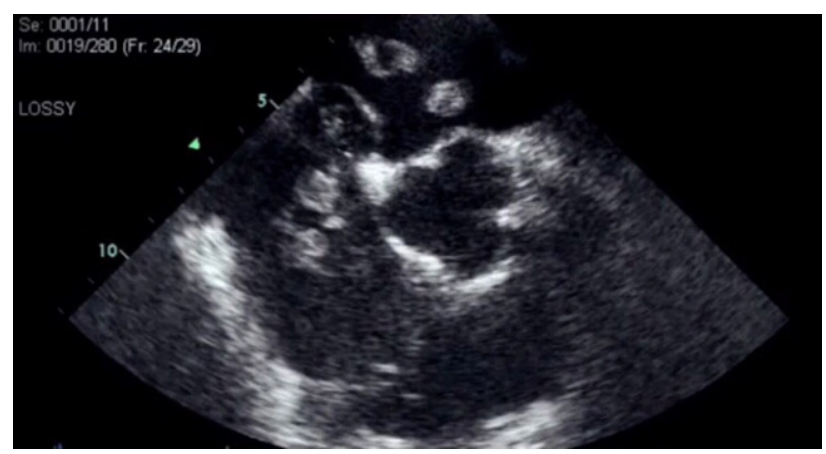

Fig. 1 Transoesophageal echocardiogram, short axis view, displaying the masses within both atria

cardiac masses, confirming the diagnosis of 'heart thrombi'.

Conflict of interest D. Afendoulis, N. Papagiannis, M. Moutafi, G. Panagi, P. Voutas, S. Garoufalis, N. Smyrnioudis and A. Kartalis declare that they have no competing interests.

Open Access This article is licensed under a Creative Commons Attribution 4.0 International License, which permits use, sharing, adaptation, distribution and reproduction in any medium or format, as long as you give appropriate credit to the original author(s) and the source, provide a link to the Creative Commons licence, and indicate if changes were made. The images or other third party material in this article are included in the article's Creative Commons licence, unless indicated otherwise in a credit line to the material. If material is not included in the article's Creative Commons licence and your intended use is not permitted by statutory regulation or exceeds the permitted use, you will need to obtain permission directly from the copyright holder. To view a copy of this licence, visit http://creativecommons.org/licenses/by/4.0/. 
Fig. 2 a CT pulmonary angiography (CTPA), sagittal view, depicting the presence of masses within the right atrium (red arrow). b CTPA, axial view, depicting bilateral pulmonary embolism (red arrow)
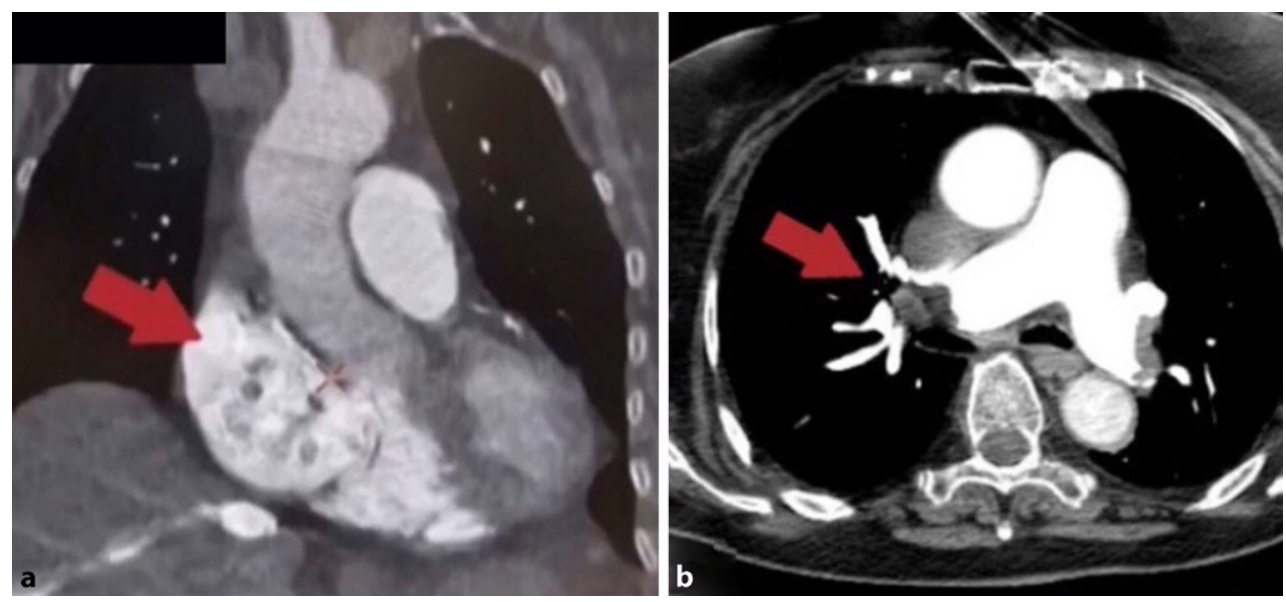

\section{References}

1. Kearon C, Akl EA, Ornelas J, et al. Antithrombotic therapy for VTE disease: CHEST guideline and expert panel report. Chest. 2016;149:315-52.
2. Meyer G, Vicaut E, Danays T, et al. Fibrinolysis for patients withintermediate-risk pulmonary embolism. NEngl J Med. 2014;370:1402-11.

3. Konstantinides SV, Vicaut E, Danays T, et al. Impact of thrombolytic therapy on the long-term outcome of intermediate-risk pulmonary embolism. JAm Coll Cardiol. 2017;69:1536-44. 